\title{
Physical Processes Affecting Microbial Habitats and Activity in Unsaturated Porous Media
}

\author{
D. Or \\ Department of Civil and Environmental Engineering \\ University of Connecticut, Storrs, CT 06269-2037, USA
}

\author{
العمليات الفيزيائية المؤثرة على المستعمرات والأنشطة الميكروبية في الوسط \\ المسامي غير المشبعرات والايشع

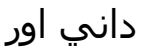

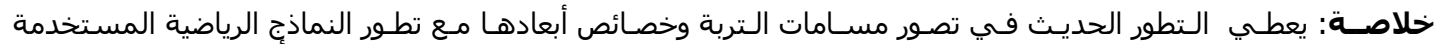

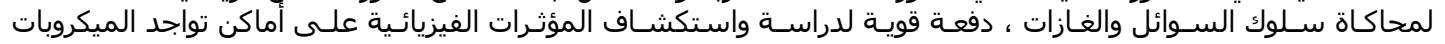

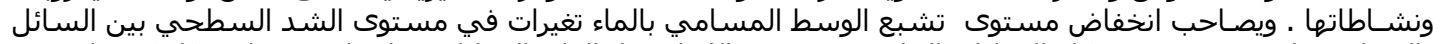

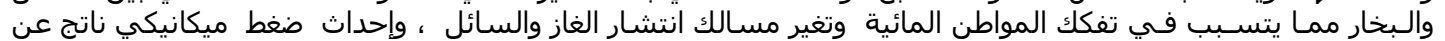

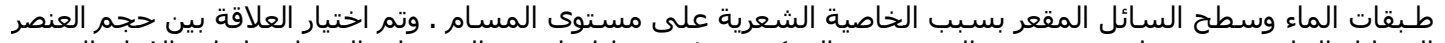

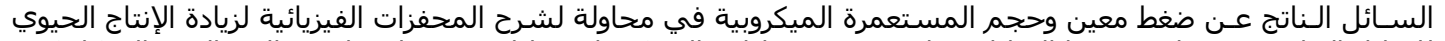

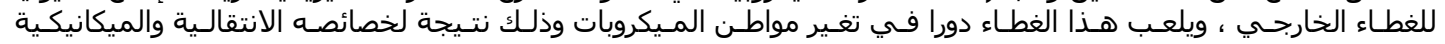

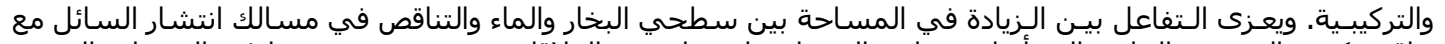

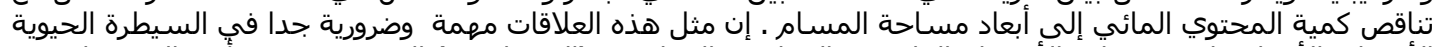

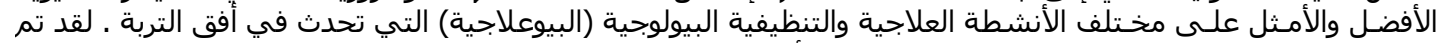

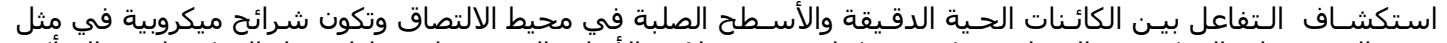

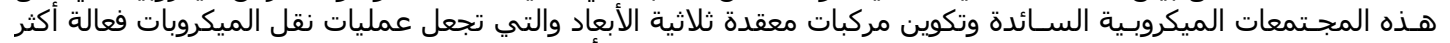

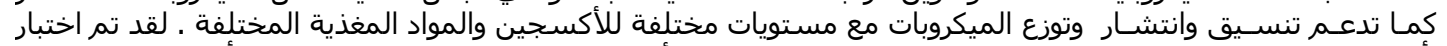

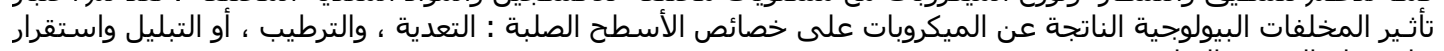

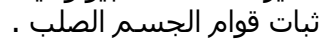

\begin{abstract}
Recent advances in soil pore space visualization and geometrical characterization coupled with improved models for liquid and gaseous behaviour provide the impetus for examination of physical influences on microbial habitats and activity. Desaturation of a porous medium is accompanied by marked changes in liquid-vapour interfacial configurations, which result in confinement and fragmentation of aquatic habitats, alteration of liquid and gaseous diffusion pathways, and introduction of mechanical stresses exerted by films and receding menisci. At the pore scale, we examine relationships between liquid element size (at a given potential) and typical organism or colony size, in an attempt to explain physical triggers for enhanced biological production of extracellular polysaccharides (EPS) coating. The role of EPS in habitat alteration is deduced from its structural, mechanical and transport characteristics. The interplay between increasing liquid-vapour interfacial area and decreasing liquid diffusion pathways with decreasing water content can be formulated as a function of pore space geometry. Such relationships are potentially important for optimal biological control of various bioremediation activities taking place at the soil profile scale. Interactions between microorganisms and solid surfaces are investigated in the context of adhesion and formation of biofilms. In such prevailing microbial communities, EPS forms complex three-dimensional structures that facilitate efficient transport processes and support a rich spatial arrangement of microorganisms with different affinities to oxygen and various nutrients. Effects of microbial activity on properties of solid surfaces including weathering and wettability, and structural stabilization of the solid matrix by biological products are examined.
\end{abstract}

Keywords: Microbial, unsaturated, porous media, organism, EPS, bioremediation, biofilm, bio-filter, bacteria, diffusion, hydraulic conductivity, soil structure.

A review of soil physics and hydrologic literature reveals that despite remarkable advances in soil characterization and sophisticated physical process modeling, the role of microbiological activity in controlling micro- and macro-scale fluxes and its potential impact on soil structural and transport 
properties is largely ignored. As Gardner (1993) stated: "Soil flora and fauna may be inconvenient for the soil physicist, but even we should be taking them seriously and be thinking and writing sensibly about them." Similarly, the microbiological literature is plagued with oversimplified depiction of natural environments and physical processes affecting microbial activity in unsaturated soils. Considering the importance and ubiquity of microbiological processes, the increasing reliance on biological processes to remedy polluted soils, and the use of the unsaturated zone of agricultural soils as an active bio-filter for wastewater reuse, bridging these gaps is a timely and necessary undertaking.

Recent improvements in modeling pore-scale liquid and gaseous behavior have altered some of the oversimplified concepts of static (Tuller et al., 1999; Or and Tuller, 1999) and dynamic (Friedman, 1999) interfacial processes. Concurrent advances in biological microsensors, confocal microscopy, and in fluorescent in-situ hybridization (FISH) methods offer a potential for analyzing complex in situ microbial community structure and function without traditional bias of cultivation methods (Okabe et al., 1999; Lipski et al., 2001). This review is aimed at elucidating primary physical processes influencing microbial habitats and activity in unsaturated agricultural soils by focusing on the fragmentation of aquatic habitats with concurrent changes in liquid and gaseous diffusion pathways during desaturation. These physical changes trigger an array of biological responses including enhanced production of extracellular polysaccharides (EPS) that form the biofilm matrix and serve as a protective coating for the embedded bacterial cells (Roberson and Firestone, 1992; Chenu and Roberson, 1996).

The reduction in contiguous liquid volumes affects substrate and gaseous diffusion, and reduces mobility of bacteria and microbiovorous grazers (Savin et al., 2001). The largest impact of liquid reconfiguration is on diffusion; a key process in most aspects of bacterial biology (Koch, 1990). The reduction in aqueous continuity and reduced liquid film thickness as soils dry reduces nutrient (and toxic excretion) diffusion rates to/from bacterial communities. In contrast, liquid-vapor interfacial area and gaseous phase continuity increase with decreasing water content, resulting in enhancement of gaseous diffusion and improved exchange with the atmosphere. The interplay between increasing liquid-vapor interfacial area and decreasing liquid diffusion pathways with decreasing water content (Skopp, et al., 1990) is potentially important for biological control of wastewater reuse and for bioremediation activities taking place in a soil profile (Huesemann, 1994).
Desaturation affects diffusion processes at a continuum of scales ranging from diffusion within individual microbial colonies to diffusion at the soil profile scale. Discrepancies between successful laboratory experiments and failures under field conditions can be attributed to incomplete consideration of physical constraints operating at the various scales; diffusion processes in particular. Diffusion constrains the spatial arrangement of microbial colonies in soil pore spaces, their size and thickness, and internal arrangement of bacterial strains within a bacterial community. Such spatial distributions can affect transport and mechanical properties of soils as will be discussed below.

In a recent review of microbial biofilms Davey and O'toole (2000) stated that: "our perception of bacteria as unicellular life forms is deeply rooted in the pure-culture paradigm". Observations in a variety of natural habitats have established that microbes persist attached to solid surfaces within structured biofilms and not free floating. Since an individual bacterium is unable to modify its environment they aggregate and form a community that provides a certain degree of shelter and homeostasis. A key component of such microbial micro-environments is the surrounding extrapolymeric matrix (EPS, protein, and other substances). EPS forms complex three-dimensional structures that facilitate efficient transport processes and support a rich spatial arrangement of microorganisms with different affinities to oxygen and various substrates (Watnick and Kolter, 2000; Okabe et al., 1999).

Microbial colonies or biofilms can significantly reduce the pore space available for water flow, resulting in a reduction in the hydraulic conductivity, termed biological clogging (Avnimelech and Nevo, 1964; Okubo and Matsumoto, 1979; Baveye et al.,1998). Reduction in saturated hydraulic conductivity up to four orders of magnitude has been observed. Experiments in bioclogging of unsaturated soils under controlled laboratory conditions are virtually non-existent; hence it is unclear whether the presence of immersed biofilms will accentuate the highly nonlinear decrease in unsaturated hydraulic conductivity. Under unsaturated conditions the role of biofilms is likely to be dependent on spatial arrangement and extent, and their intrinsic transport properties.

The lack of a coherent conceptual framework is coupled with rapid progress and emergence of highly specialized jargon that not only form disciplinary barriers, but also hamper efforts to assemble a more realistic picture of the complex interactions described above. Thus progress in these areas requires interdisciplinary and collaborative effort. The objective 


\section{PHYSICAL PROCESSES AFFECTING MICROBIAL HABITATS AND \\ ACTIVITY IN UNSATURATED POROUS MEDIA}

of this work is to provide an overview of primary physical processes and constraints affecting microbial habitats and microbial activity in unsaturated soils at the pore scale, and highlight implications for behavior at the soil profile scale. Aspects of microbial activity and response on soil pore space, soil structure, and soil transport and water retention properties will be discussed.

\section{Overview of Physical and Microbial Processes in Unsaturated Soils}

DIFFUSION PROCESSES AND MiCROBIAL ACTIVITY IN UNSATURATED SOILS: The reduction in conducting liquid pathways as soil dries reduces liquid and nutrient diffusion rates at all scales, particularly at the microscale of individual bacterial communities and within a biofilm. Macroscopically, the primary effect is on gaseous diffusion and convective supply of substrates. As water content decreases soil air content and liquid-vapor interfacial area increase resulting in enhancement of gaseous diffusion and improved gaseous exchange (with atmosphere) at both the micro- and macroscale. The interplay between the increase in liquid-vapor interfacial area and the decrease in liquid diffusion pathways with decreasing water content can be formulated as a function of pore space geometry and water status. Skopp et al., (1990) analyzed this interplay focusing on macroscopic diffusion coefficients to identify an "optimal" water content that maximizes microbial activity at soil sample- or profile-scales (Figure 1).

At the microscale, both, structure and position of a bacterial colony within the soil pore space are likely to play an important role in the onset of diffusional constraints for different liquid configurations. Under "dry" conditions soil water is primarily in the form of films held by surface forces. The thickness of the liquid film coating solid surfaces, and hydraulic connectivity between the liquid-filled crevices, play a primary role in determining substrate diffusion rates (Mills and Powelson , 1996). Rivkina et al. (2000) show data from Siberian permafrost (Figure 2) suggestive of diffusional constraints on amounts of ${ }^{14} \mathrm{C}$-lable acetate incorporation imposed by thin liquid films (film thickness is a function of ambient temperature). For relatively dry soils, the relationships between soil water potential and film thickness are readily available according to Tuller et al. (1999).

Even at the biofilm scale, dramatic changes in diffusion rates are experienced as soil dries (Chenu and Roberson, 1996; Holden et al., 1997). Attempts to quantify such effects on microbial activity have focused on individual processes, such as effects of
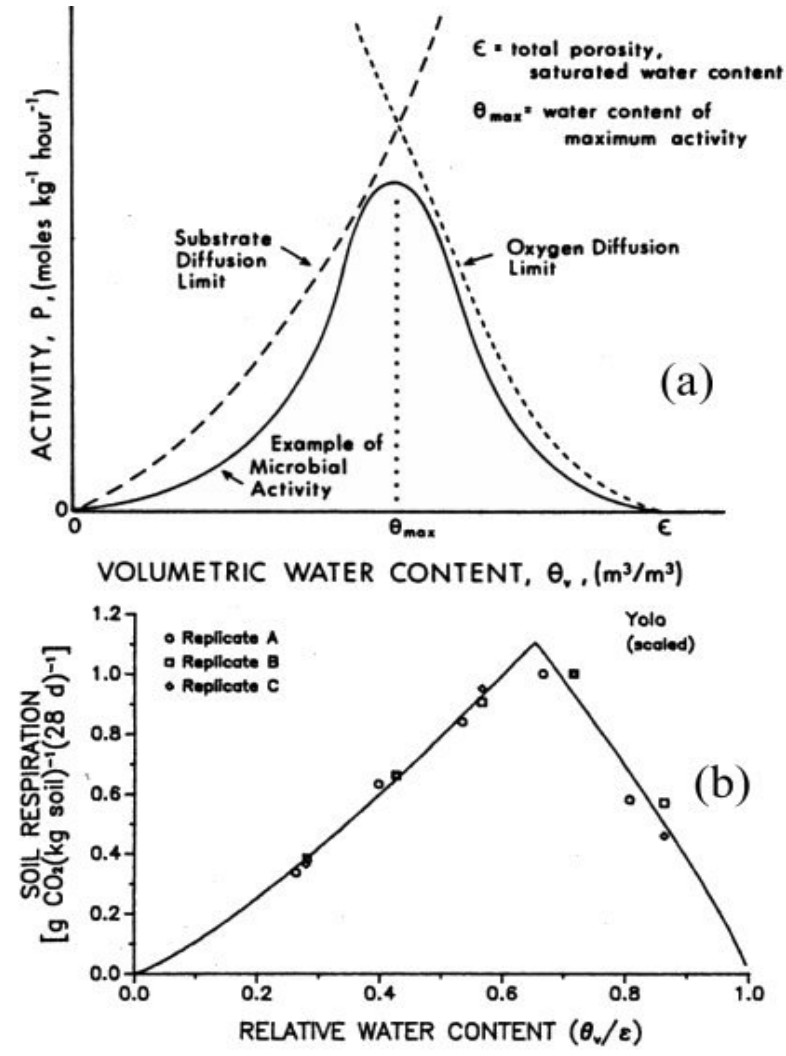

Figure 1. (a) A conceptual sketch of (aerobic) microbial activity as a function of water content; and (b) comparison with data for Yolo soil (Skopp et al., 1990).

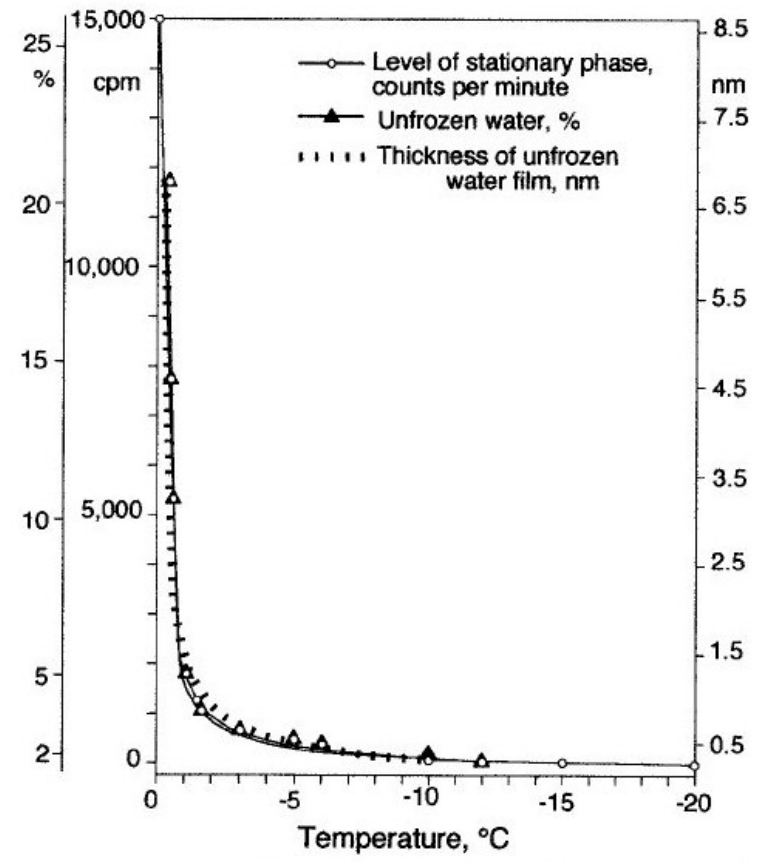

Figure 2. Incorporated ${ }^{14} \mathrm{C}$ - labeled acetate by native bacterial population in Siberian permafrost (cpm) vs. measured amounts of unfrozen soil water (\% mass) and estimated film thickness (nm) (Rivkina, et al., 2000). 
matric potential on diffusion through the EPS coating (Chenu and Roberson, 1996), effects of matric vs. solute potentials on nitrification (Stark and Firestone 1995), and effects of pore space heterogeneity on nutrient acquisition.

A unifying theory is clearly needed, as Crawford et al. (1993) state: "it is clear from the order of magnitude considerations presented above that to understand the dynamics of soil microbial population it is necessary to have a quantitative framework which encapsulates soil structure". By corollary, it will require detailed consideration of liquid organization as well.

EFFECTS OF MICROBIAL ACTIVITY ON SOIL HYDRAULIC CONDUCTIVITY AND WATER RETENTION: The formation and growth of microbial biofilms, and their extent and spatial arrangement almost certainly affect soil transport, retention, and structural properties.

Effects on hydraulic conductivity: Microscopic observations in bioclogging studies indicated that in some cases a continuous biofilm covering the grains had developed (Cunningham et al., 1991), while in other cases discrete microcolonies were detected (Vandevivere and Baveye, 1992). Observations made in a twodimensional glass network micromodel study indicated that the biomass accumulated both as biofilms covering the pore walls and discrete aggregates clogging the pore throats (Kim and Fogler, 2000). This study also revealed that changing from nutrient to starvation conditions resulted in partial biofilm sloughing and permeability recovery (Figure 3 ).

Estimates of biofilm thickness were in the range of $15 \mu \mathrm{m}$ (for $0.12 \mathrm{~mm}$ sand grains) to $150 \mu \mathrm{m}$ (for $0.7 \mathrm{~mm}$ sand grains), which could explain the significant porosity and permeability reductions. Rittmann (1993) claimed that the most important factor determining bacterial deposition patterns is substrate supply rate and proposed a normalized surface loading criterion, which is defined to be the actual substrate flux (i.e. rate of removal per unit surface area) divided by the minimum flux capable of supporting a deep biofilm. When this number is larger than 1 , a continuous biofilm develops, and when less than 0.25 patchy biofilms develop, mostly in pore throats. Additional geometrical (pore size) (Vandevivere and Baveye, 1992), and hydrodynamic factors (Nevo and Mitchel, 1967) also affect the spatial arrangement of bacterial populations.

Modeling efforts for bioclogging effects on permeability reduction were based on different approaches to describe the saturated hydraulic conductivity of the clean bed: a single cylindrical capillary model (Okubo and Matsumoto, 1979), cut-andrejoin bundle of capillaries models (Taylor et al., 1990;

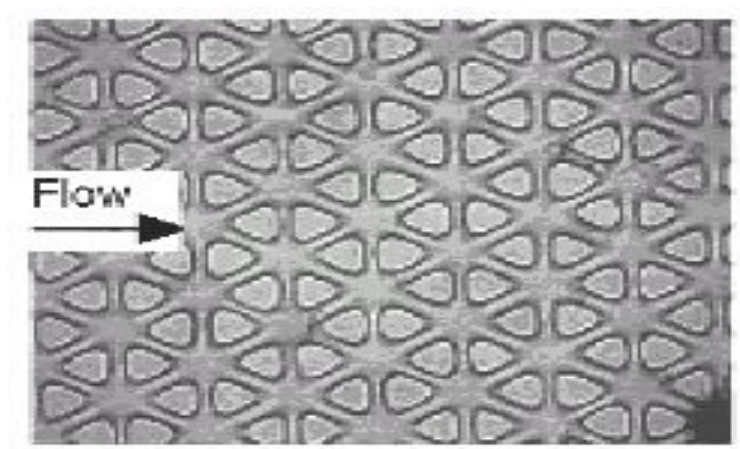

$P V=12$ (3 hrs of sucrose injection)

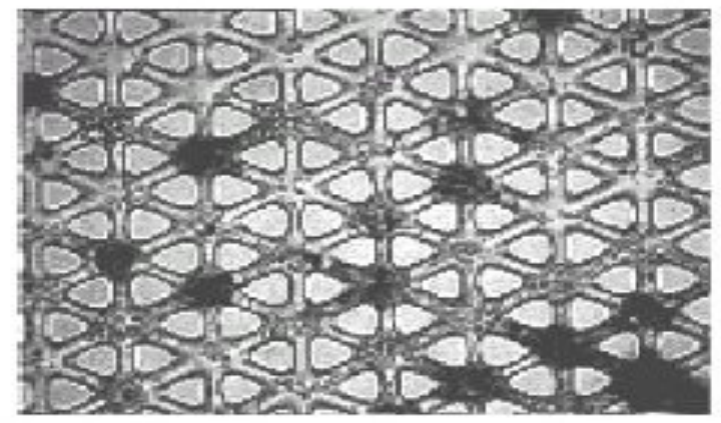

$P V=120(1.3$ days of sucrose injection, 2.5 hrs thefore huffer injection)

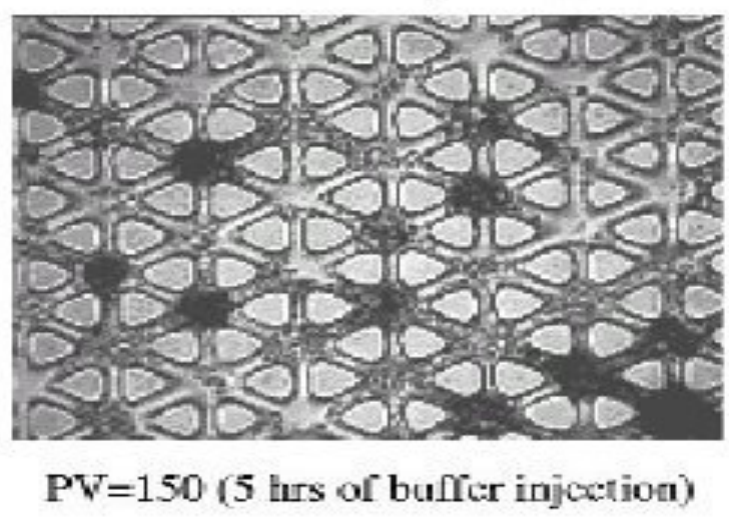

Figure 3. Dynamics of bioclogging in a glass micromodel (Kim and Fogler, 2000).

Vandevivere et al., 1995) and the Kozeny-Carmen equation (Taylor et al., 1990; Vandevivere et al., 1995). In all the above models a uniform narrowing of the pore space by the continuous developing biofilm was assumed, which is highly unlikely. A more realistic assumption is that biofilms develop preferentially in larger pores with larger water flow (substrate supply, toxic compound removal), whereas for discrete colonies, a probable location for initial bacterial deposition is at pore constrictions and near grain contacts. Such microscopic biofilm thickening and single bacterial deposition patterns are characterized by different macroscopic permeability-porosity relationships along the bio-clogging process. Another 


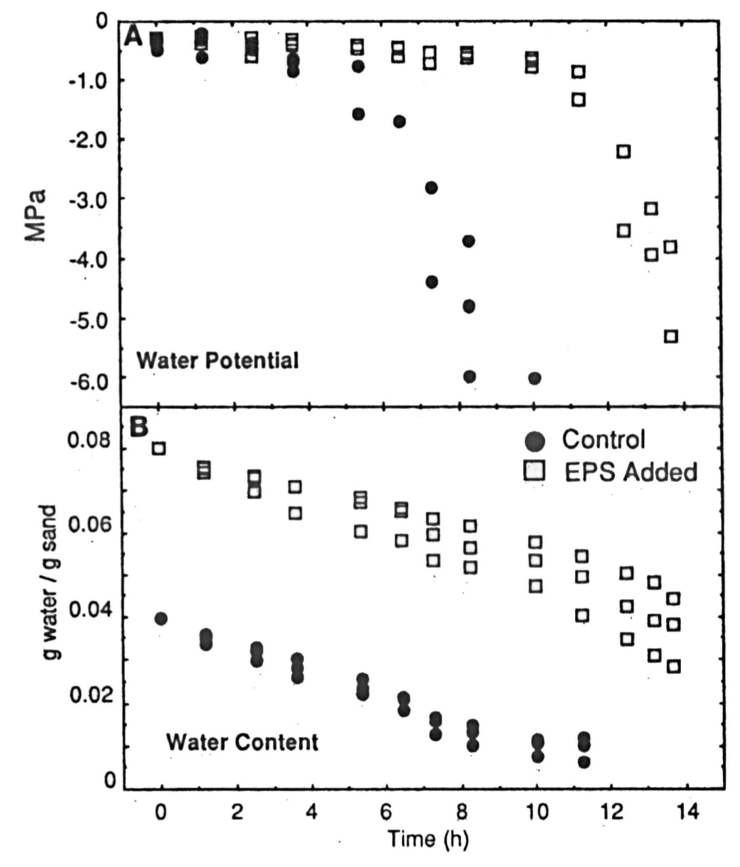

Figure 4: Changes in (a) water potential, and (b) water content during $14 \mathrm{~h}$ of drying in sand with and without EPS added (Roberson and Firestone, 1992).

bioclogging mechanism in saturated porous media is gas (e.g., methane) release and consequent pore blockage due to entrapped bubbles (Sanchez de Lozada et al., 1994).

Effects on water retention properties: Under unsaturated conditions with fragmented aquatic habitats it is likely that bacteria will form discrete colonies where a biofilm is discontinuous, thin, and covers only a fraction of soil mineral surfaces. Consequently, the different wettability properties of such organic "spots" on mineral surfaces will produce soil water retention characteristic that exhibit a fractional wettability behavior (Bradford and Leij, 1996; Ustohal et al., 1998).

In the presence of appreciable amounts of EPS, soil water-holding capacity increases (Figure 4), as demonstrated by Roberson and Firestone (1992) and Chenu (1993). The increased water retention during drying is attributed to both the direct addition of EPS with its very high water holding capacity (up to $>50 \mathrm{~g} / \mathrm{g}$ ) and also to creation of a more open pore space and separation between solid particles with a fibrous network attached to clay particles (Chenu, 1993). However, upon rewetting of kaolinite-EPS complexes, a decrease in the amount of water absorbed was observed (Chenu, 1993), probably due to irreversible structural changes in EPS during drying (Holden et al., 1997), and perhaps due to changes in clay wettability.

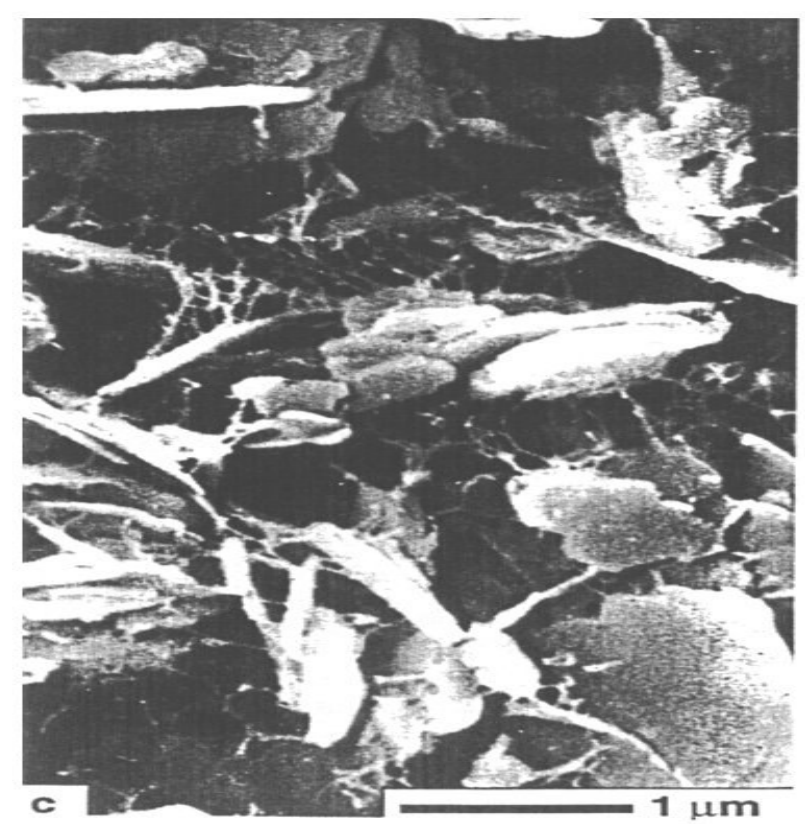

Figure 5. EPS scleroglucen adsorbed on kaolinite particles (w.c. $1.5 \mathrm{~g} / \mathrm{g}$ ) (Chenu and Tessier, 1995).

EFFECTS OF MiCROBIAL ACTIVITY ON SOIL STRUCTURE: Formation of microbial colonies adhered to solid surfaces has an important effect on soil structural properties primarily through the formation of polymer bridges that bind soil particles (Chenu and Guerif, 1991; Chenu, 1993). The microbial enmeshing of soil particles shown in Figure 5 has a dual role in forming microaggregates, and more importantly their stabilization (Oades, 1993). The spatial arrangement of microbial activity (hence microbial debris) likely plays an important role in the structural efficiency of such stabilizing agents. Moreover, we expect that the soil strength (and structural stability) acquired by accumulation of microbial debris would be strongly correlated to the mechanical properties of EPS forming the bacterial colonies (Thwaites and Mendelson, 1991). As clearly illustrated in Figure 5, the presence of EPS helps maintain an open structure among clay particles (and at an aggregate bed scale). Such an open structure is favorable for soil transport properties. Hadas et al. (1994) attributed the increase in aggregate size and strength one week after plant residue addition to reinforcement by fungi hyphae, whereas changes appearing after the sixth week were attributed to bacterial secretions. Following intense colonization of wheat rhizosphere by EPS-producing bacteria, Amellal et al. (1998) observed significant soil aggregation and concluded that $\mathrm{P}$. agglomerans plays an important role in soil water regulation by improving aggregation. 
MORPHOLOGICAL AND FUNCTIONAL ADAPTATION OF Microbial Colonies DurING SoIl Drying: Studies have shown that under drying conditions bacterial colonies respond by enhanced production of EPS (Roberson and Firestone, 1992). Additionally, dehydration of non-submerged biofilms will cause collapse of the open structure and affect transport properties of the biofilm (Holden et al., 1997). An illustration of the morphological changes in the EPS 3D structure is shown in Figure 6. In contrast to the fibrous and open structure on the left (wet soil), the EPS becomes dense and amorphous. It was hypothesized that such a change reduces rates of water loss and possibly traps nutrients within the dense protective coating thereby assisting bacteria to survive desiccation (Chenu, 1993).

An important aspect of such changes is the mechanical response of EPS to changes in its hydration status. It has been observed with similar biopolymers (Thwaites and Mendelson, 1991) that the tensile strength and the Young's modulus increase by several orders of magnitude as the relative humidity (or water potential) decreases from near saturation. Moreover, the biopolymer changes from soft and ductile at high humidity to stiff and brittle at low humidity. Knowledge concerning these mechanical changes could help explain the role of EPS in providing mechanical and diffusional protection for bacterial biofilms during desiccation. A related issue is the marked increase in soil strength with decreasing soil water content. It would be interesting to obtain estimates of the proportion of observed increase in soil strength attributable to the increase in the strength of EPS as a bonding agent.

\section{Conclusions}

Rapid changes in liquid and interfacial configurations in unsaturated soils present various constraints to activity of microbial communities thereby triggering an array of biological responses to changes in ambient conditions. An important constraint highlighted in the present review is the dramatic change in diffusion pathways of substrates and gases. As the energy state of soil water (matric potential) decreases, the physico-biological adjustment of microbial communities becomes more evidenced by the enhanced production of EPS. The review provides a starting point for quantitative modeling of interactions between physical (a biotic) processes and microbial adaptation in a given pore space. Ongoing research focuses on pore scale interplay between solution and gaseous exchange in angular pores, and on understanding of the physical consequences of enhanced EPS production on micro- and macro-scale processes and on soil macroscopic properties.

\section{References}

Amellal, N., G. Burtin, F. Bartoli, and T. Heulin. 1998. Colonization of wheat roots by an exopolysaccharide-producing Pantoea agglomerans strain and its effect on rhizosphere soil aggregation. Appl. Environ. Microbiol 64:3740-3747.

Avnimelech, Y. and Z. Nevo. 1964. Biological clogging of sands. Soil Sci. 98:222-226.

Baveye, P., P. Vandevivere, B.L. Hoyle, P.C. DeLeo, and D. Sanchez de Lozada. 1998. Environmental impact mechanisms of the biological clogging of saturated soils and aquifer materials. Crit. Rev. Environ. Sci. Technol. 28:123-191.

Bradford, S.A. and F.J. Leij. 1996. Predicting two- and three-fluid capillary pressure-saturation relationships of porous media with fractional wettability. Water Resour. Res., 32, 251-259.

Chenu, C. 1993. Clay-or-sand-polysaccharide associations as models for the interface between micro-organisms and soil: water related properties and microstructure. Geoderma 56:143156.

Chenu, C. and J. Guerif. 1991. Mechanical strength of clay minerals as influenced by an adsorbed polysaccharide. Soil Sci. Soc. Am. J. 55:1076-1080.

Chenu, C. and E.B. Roberson. 1996. Diffusion of Glucose in Microbial Extracellular Polysaccharide as Affected by Water Potential. Soil Biol.Biochem 28:877-884.

Chenu, C. and D. Tessier. 1995. Low temperature scanning electron microscopy of clay and organic constituents and their relevance to soil microstructure. Scanning Microscopy 9:989-1010.

Crawford, J.W., K. Ritz, and I.M. Young. 1993. Quantification of fungal morphology, gaseous transport and microbial dynamics in soil: an integrated framework utilizing fractal geometry. Geoderma 56:157-172.

Cunningham, A.B., W.G. Charaklis, F. Abedeen, and D. Crawford. 1991. Influence of biofilm accumulation on porous media hydrodynamics. Environ. Sci. Technol. 25:1305-1311.

Davey, M.A. and G.A. O'toole. 2000. Microbial biofilms: from ecology to molecular genetics. Microb. Molecul. Biol. Rev. 64:847-867.

Friedman, S. P. 1999. Dynamic contact angle explanation of flow rate-dependent saturation-pressure relationships during transient liquid flow in unsaturated porous media. Adhesion Sci. and Technol 13:1495-1518.

Gardner, W.R. 1993. A call for action. Soil Sci. Soc. Am. J. 5:14031405.

Hadas, A., E. Rawitz, H. Etkin, and M. Margolin. 1994. Short-term variations of soil physical properties as a function of the amount and $\mathrm{C} / \mathrm{N}$ ratio of decomposing cotton residues: I. Soil aggregation and aggregate tensile strength. Soil Till. Res. 32: 183-198.

Holden, P.A., J.R. Hunt, and M.K. Firestone. 1997. Toluene diffusion and reaction in unsaturated Pseudomonas putida biofilms. Biotech. Bioeng. 56:656-670.

Huesemann, M.H. 1994. Guidelines for land-treating petroleum hydrocarbon-contaminated soil. J. Soil Contamin 3:1-20.

Kim, D.S. and H.S. Fogler. 2000. Biomass evolution in porous media and its effects on permeability under starvation conditions. Biotech. Bioeng. 69:47-56.

Koch, A.L. 1990. Diffusion the crucial process in many aspects of the biology of bacteria. Adv. Microbiol. Ecology 11:37-70.

Lipski, A., U. Friedrich, and K. Altendorf. 2001. Application of rRNA-targeted oligonucleotide probes in biotechnology. Appl Microbiol Biotechnol 56:40-57.

Mills, A.L. and D.K. Powelson. 1996. Bacterial interactions with surfaces in soils. In: Bacterial Adhesion, M. Fletcher (ed.), pp. 25-57, Wiely-Liss, New York.

Nevo, Z. and R. Mitchel. 1967. Factors affecting biological clogging of sand associated with ground water recharge. Water Res. 1:231-236. 


\section{PHYSICAL PROCESSES AFFECTING MICROBIAL HABITATS AND ACTIVITY IN UNSATURATED POROUS MEDIA}

Oades, J.M. 1993. The role of biology in the formation, stabilization, and degradation of soil structure. Geoderma 56:377-400.

Okabe, S., H. Satoh, and Y. Watanabe. 1999. In situ analysis of nitrifying biofilms as determined by in situ hybridization and the use of microelectrodes. Appl. Environ. Microbiol. 65:3182-3191.

Okubo, T. and J. Matsumoto. 1979. Effect on infiltration rate biological clogging and water quality changes during artificial recharge. Water Resour. Res. 15:1536-1542.

Or, D. and M. Tuller. 1999. Liquid retention and interfacial area in variably saturated porous media: Upscaling from pore to sample scale model. Water Resour. Res. 35(12), 3591-3605.

Rittmann, B.E. 1993. The significance of biofilms in porous media, Water Resour. Res. 29:2195-2202.

Rivkina, E.M., E.I. Friedmann, C.P. Mckay, and D.A. Gilichinsky. 2000. Metabolic activity of permafrost bacteria below the freezing point. Appl. Environ. Microbiol. 66:3230-3233.

Roberson E.B. and M.K. Firestone. 1992. Relationship between desiccation and exopolysachharide production in soil Pseudomonas sp. Appl. Environ. Microbiol. 58:1284-1291.

Roberson, E.B., C. Chenu, and M.K. Firestone. 1993. Microstructural changes in bacterial exopolysccharides during desiccation. Soil Biol.Biochem. 25:1299-1301.

Sanchez de Lozada, D., P. Vandevivere, P. Baveye, and S. Zinder. 1994. Decrease of the hydraulic conductivity of sand columns by Methanosacrina barkeri. World J. Microbiol. Biotechnol., 10:325333.

Savin, M.C., J.H. Gorres, D.A. Neher, and J.A. Amador. 2001. Biogeophysical factors influencing soil respiration and mineral nitrogen content in an old field soil. Soil Biol. Biochem. 33:429438.
Skopp, J., M.D. Jawson, and J.W. Doran. 1990. Steady-state aerobic microbial activity as a function of soil water content. Soil Sci. Soc. Am. J. 54:1619-1625.

Stark, J.M. and M.K. Firestone. 1995. Mechanisms for soil moisture effects on activity of nitrifying bacteria. Appl. Environ. Microbiol. 61:218-221.

Taylor, S.W., P.C.D. Milly, and P.R. Jaffe. 1990. Biofilm growth and the related changes in the physical properties of porous medium: 2. Permeability. Water Resour. Res. 26:2161-2169.

Thwaites, J.J. and N.H. Mendelson. 1991. Mechanical behavior of bacterial cell walls. Adv. Microb. Physiol. 32:173-223.

Tuller, M., D. Or, and L.M. Dudley. 1999. Adsorption and capillary condensation in porous media: Liquid retention and interfacial configurations in angular pores. Water Resour. Res. 35(7): 1949-1964.

Ustohal, P., F. Stauffer, and T. Dracos. 1998. Measurement and modeling of hydraulic characteristics of unsaturated porous media with mixed wettability. J. Contaminant Hydrol. 33:5-37.

Vandevivere, P. and P. Baveye. 1992. Saturated hydraulic conductivity reduction caused by aerobic bacteria in sand columns. Soil Sci. Soc. Am. J. 56:1-13.

Vandevivere, P., P. Baveye, D. Sanchez de Lozada, and P. DeLeo. 1995. Microbial clogging of saturated soils and aquifer materials: Evaluation of mathematical models. Water Resour. Res. 31:2173-2180.

Watnick, P. and R. Kolter. 2000. Biofilm, City of microbes. J. Bacter. 182:2675-2679.

Received August 2002.

Accepted November 2002 